JASNA GOLUBIĆ, Ph.D. ${ }^{1}$

(Corresponding author)

E-mail: jgolubic@fpz.hr

ZORAN VOGRIN, M.Sc. ${ }^{1}$

E-mail: zvogrin@fpz.hr

EDUARD MISSONI, Ph.D. ${ }^{1}$

E-mail: emissoni@fpz.hr

1 University of Zagreb,

Faculty of Transport and Traffic Sciences

Vukelićeva 4, 10000 Zagreb, Croatia
Safety and Security in Traffic

Review

Submitted: May 2, 2016

Accepted: Sep. 21, 2016

\title{
DYNAMIC ANTHROPOMETRIC CHARACTERISTICS OF PEDESTRIANS IN CASE OF CAR COLLISION
}

\begin{abstract}
The paper gives an overview of the specific features of anthropometric characteristics of humans - pedestrians in case of car accidents involving pedestrians and cars. Here, special attention has been paid to the configuration of the human body while moving, which is in turn related to the initial conditions of a collision. Special part of biomechanics in humans refers to their moving, where human's walk has a specific posture as a mechanical phenomenon. Based on the carried out analysis the need has been observed for a classification of anthropologic variables by means of which the dynamic inertia moments of a walking human can be calculated, as well as the human, who hit by a car in a traffic accident flies along a production curvilinear path. With the development of ergonomics, and the accompanying increased application of anthropometry, the static anthropometry was abandoned, since the humans are considered highly variable in their dimensions, which is extremely important for the dynamic analysis of the human body posture in the collision process.
\end{abstract}

\section{KEY WORDS}

anthropometric characteristic; pedestrians; car collision; dynamic anthropometric variables;

\section{INTRODUCTION}

Application of mechanics on the living systems, including humans is an area of mechanics that is called biomechanics. A special case of biomechanics of humans refers to their movement, where human walk has a specific position as a mechanical phenomenon.

As an especially expressed simplification of the problem is the ignoring of the rotation in solving the problem, thus considering the collision participants either the vehicles or vehicle and a human - as particles.

In available domestic and foreign literature which refers to the study of the traffic accident problems, usually the movements of pedestrians (walk and being thrown-off) are calculated according to the calculations of energy and work that are generated in the impact process between the solid body (vehicle) and the pedestrian [12]. In this way the pedestrian is considered in a very simplified manner as a particle of mass $m$ which collides with the vehicle, also a particle but of mass $M$.

When in these calculations the problem is to be given a dynamic character of vehicle-pedestrian collision, which means not particles any more, then for the model of the human the bodies as sticks are selected, and they form a system with two or more masses. To this mechanical system one can apply e.g. the law of momentum, which can be in general a space system, but it can also be simplified and transformed into a planar system. When the problem is approached in this way then this results in quite a complex mathematical procedure from which, of course, with the recognition of numerous assumptions the following can be calculated:

- impact force, and

- rotation and translation speeds of system elements.

For the sake of simplicity let us assume that the model consists of two sticks, each of which has the meaning of a half of the pedestrian body, then there occur in the calculation two dimension-less coefficients which depend on the size and distribution of masses of the model of upper and lower part of the pedestrian body. And finally, when the values of these coefficients are determined for the concrete example, then these coefficients are again input into the equations of dynamic balances from which the impact force and speed are calculated, after which the problem is again (for the sake of simplicity) reduced to the study of collision of particles.

Not getting here into more detail of the problem of studying the movement of the pedestrian body in the collision process, which is considered far more complex in the actual conditions in relation to the simplified models and methods of calculation that are used in everyday practice in investigation, the decision here has been only to present the value of the impact of 
distribution of masses and dimensions of humans on their behaviour in possible collision with the vehicle, as well as the anthropometric characteristics of the pedestrians.

It is, namely, known that in determining the initial positions and conditions of the humans using subsequent reconstruction of events, often only final conditions can be used. Therefore a question is asked - is it possible and in which way to use static results to determine the dynamic phenomena in order to use these results to make valid conclusions about the biomechanical processes in vehicle-pedestrian collision.

According to the usual practice the parts of the human body are divided into the body, head, arms and legs. In this way usually the measurements of anthropometric values are carried out, of course, with more or less detailed subdivisions. Every elementary body mass can be expressed in this way with the percentage of its share in the total mass of the human body.

Based on such distribution of human body elements, the arm of a human can be presented with a model of assembled but unique stick which can rotate about a point located in the centre of the shoulder joint. If furthermore the homogeneity of this stick is assumed, then the inertia moment of the stick $(I)$ is

$I=\frac{m \cdot I^{2}}{3}$

where:

$m$-mass of one arm (kg)

I -length of the arm (m)

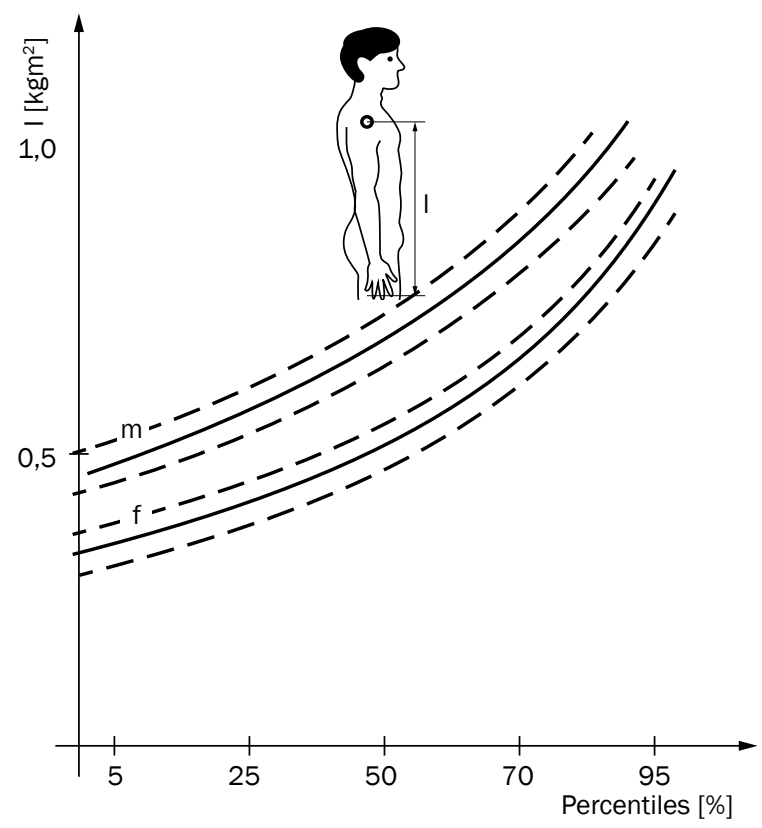

Figure 1 - Graphical presentation of the distribution of dynamic moments of inertia of human arm ( $m$ - male and $f$ - female)

Figure 1 presents the distribution of dynamic moments of inertia of human arm depending on the distribution per percentiles. Broken lines mark the areas of deviation of measured values.

Regarding different dimensions of arms and also different assigned masses, and depending on the gender and dimension frequencies, the values of the dynamic moment of inertia vary as well.

Let us consider now one simple movement of the human arm. Let it be planar motion of the arm in which the initial position is a lowered arm, which from stationary condition rises by about $180^{\circ}$ and stops there as shown in Figure 2. Thus, the initial and final speeds equal 0 , and the same is with the accelerations. Furthermore, it is assumed that the centre of rotation in the shoulder joint is 0 fixed, although this is not the case in reality. The ideal kinematic diagrams for such movement are presented in Figure 3, from which it follows that the movement is assumed to be symmetrical.

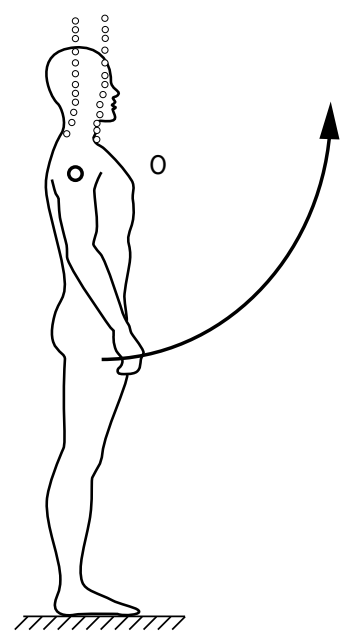

Figure 2 - Presentation of the selected movement of the human arm
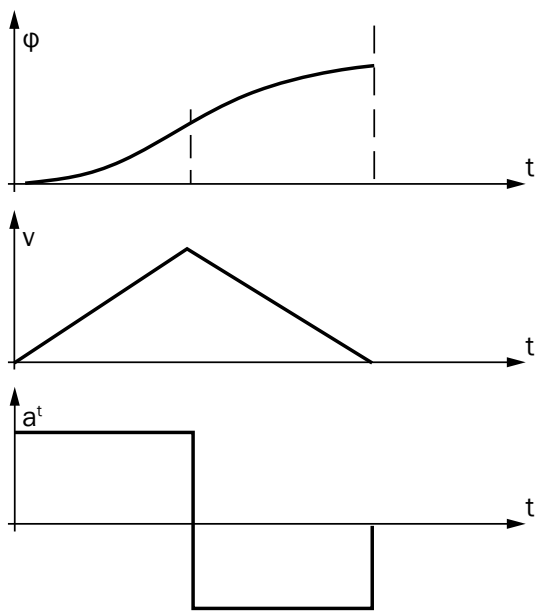

Figure 3 - Idealised kinetic diagrams of assumed movement of the respondent's arm

$(\varphi$ - angle of movement of the respondent's arm in correlation of time $t$, $a^{t}$ - acceleration, $v$ - speed, $t$ - time) 
The measurements of acceleration and speeds [1], which were realised by means of accelerometer which was fixed to the respondent's hands, from which pulses were transferred to the measuring amplifier with integrator, and from there to the oscilloscope's display, indicate a completely different appearance of the diagram. To describe the movement, even such as in this example, the simplified model of physical pendulum for the model of arm cannot be used, since masses that participate in the movement make the arm in terms of its dynamic moment of inertia dependent on the position of the arm in relation to the body. This fact refers to further studies from which for certain positions of arms the dynamic moments of inertia could be determined taking into consideration also those muscle masses that participate in the realisation of the movement at that moment.

\section{ANTHROPOMETRIC CHARACTERISTICS OF PEDESTRIANS}

As well known, for the purposes of determining the initial mechanical conditions in which both the

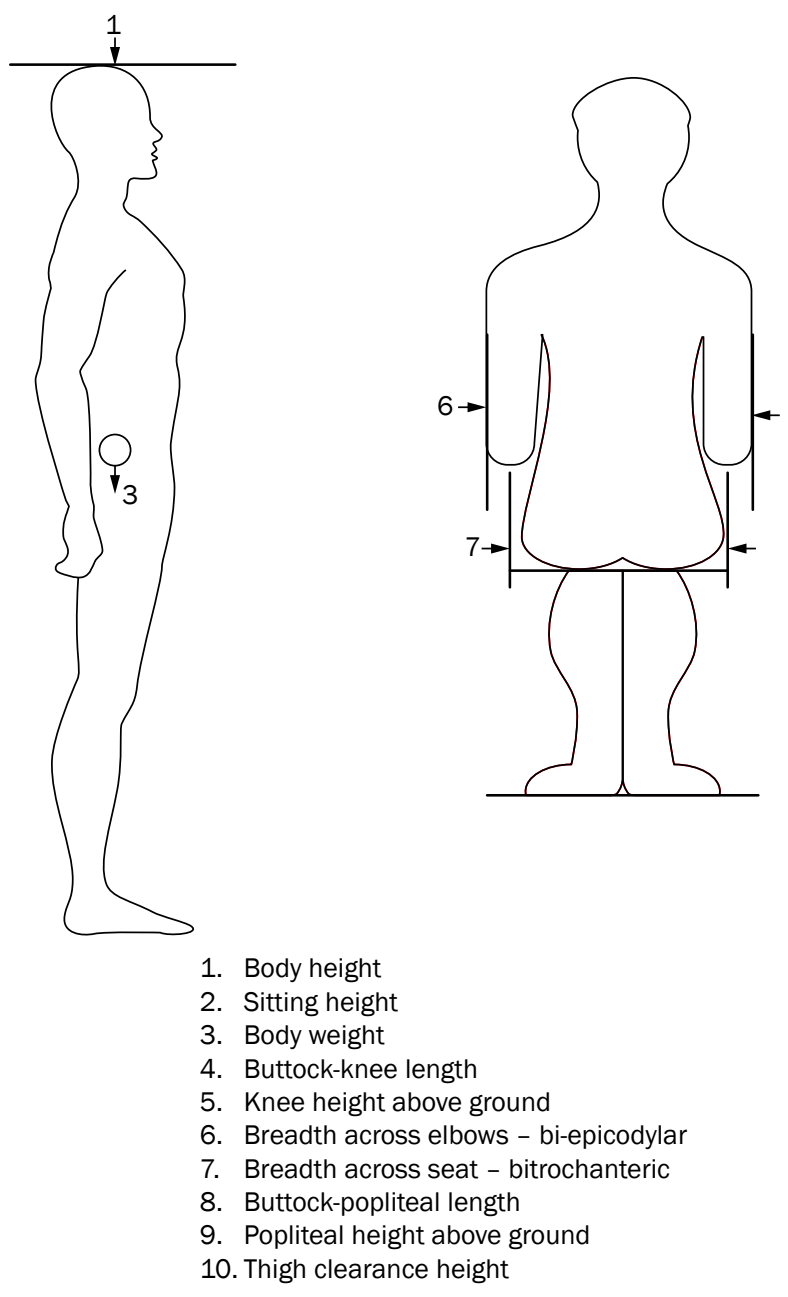

pedestrian and vehicle were before and during the collision, it is necessary to know numerous data about the pedestrian such as their anthropometric data (Figure 4) for which it is known that they are divided, apart from age differences also according to gender and dimensional frequencies. It should be noted here immediately that this refers to the so-called static variables of anthropometric values, that in the use in case of dynamic analyses of the movement of pedestrians in the collision process have to be somehow changed or distinguished. In the available literature we could not find any special information about the dynamic anthropometric data $[3,5,6,8]$.

On the other hand, it cannot be said that the existing methods of mechanical analyses used in the investigations have no initial dynamic considerations of their own. In studying, namely, the process of vehicle hitting the pedestrian, the process of collision is divided according to different authors in several phases in which there are different relations between the vehicle and pedestrian. In these studies, different mathematical and mechanical models are used, and they

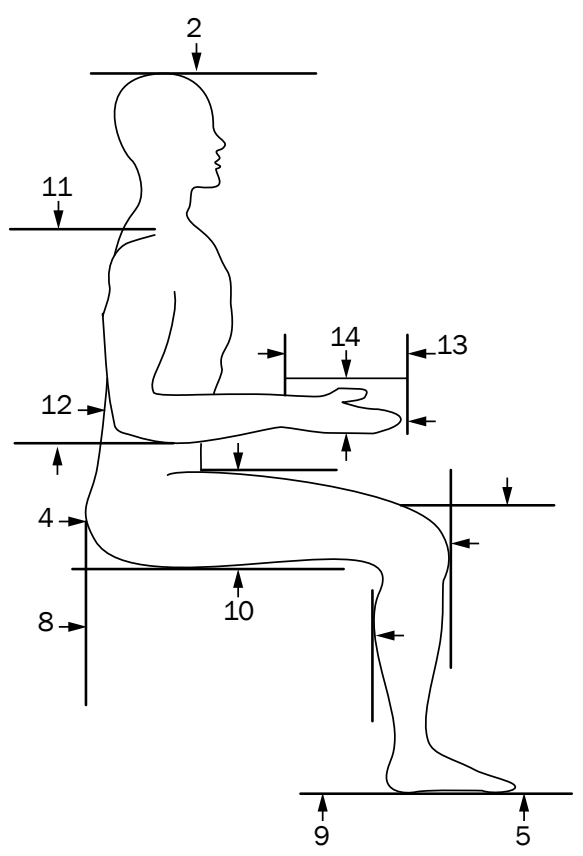

Regarding the adjustment of the tool dimensions and control devices of the workers the following is measured:

11. Shoulder-elbow length

12. Elbow-middle finger length

13. Hand length

14. Hand breadth

15. Hand grip diameter

Figure 4 - Anthropometric measurements in occupational health [3] 
represent the humans and their anthropometric characteristics by which the dynamic character is given in such way that with certain assumptions they calculate the dynamic moments of inertia of the pedestrian body or their inertia radii, of course, according to statistical anthropometric values. For the mentioned body models usually the elements of prismatic bodies are used that are arranged in simple units.

By applying the law of dynamics on the study of motion of thus assumed body system models, composed of "solid" members, it is possible to calculate some values that characterise the motion of such a system i.e. model.

However, questions still remain to which extent such a mechanical model of the system is realistic, and how truthful the calculated results are? This, namely, brings into doubt the possibility of comparing the experimental results on mechanical behaviour and motion of the dummy models hit by vehicles with realistic movements of pedestrians in traffic accidents.

The development of ergonomics, including also some kind of application of anthropometry, the static anthropometry is abandoned since the human is considered to be highly variable in their dimensions, and especially when it is assigned to their work and body motions during this work.

On the example shown applicability of dynamic moments of inertia of the arm during its movement is reflected also on the difficulties that occur in calculating the body movement in the collision process, since it is assumed that the body configuration will change in the collision process, thus also changing the dynamic inertia moments of the body.

\section{VIEW OF MATHEMATICAL METHOD}

According to data from the expertises of traffic accidents in order to calculate the traumatising forces either the law of material point pulses (i.e. quantity of movement) or the law on kinetic energy of the material point are used in the following forms:

This expression for calculating force follows from the law on pulses

$$
F=\frac{m\left(v_{k}-v_{p}\right)}{t}
$$

where:

$$
F \quad \text {-force, [N]; }
$$

$\left(v_{k}-v_{p}\right)$-fall of velocity, difference between final and initial velocity, $[\mathrm{m} / \mathrm{s}]$

$m \quad$-pedestrian body mass, [kg];

$t$-time duration of a collision, [s].

If it is considered that the duration of the collision is very short (e.g. about 0.0015 seconds), then it is obvious that it is almost impossible to determine (even assess) the fall in velocities or accelerations. From this, without further comment, the method approximation can be seen. On the other hand, the following expression is recommended for determining the traumatising force:

$F=\frac{m v^{2}}{2 s}$

where:

$F$-traumatizing force, [N];

$m$-pedestrian body mass, [kg];

$v$-car movement velocity, [m/s];

$s$-throw-off distance of pedestrian, [m].

It can be noted that this equation can be applied only in those rare cases, when the value of the throwoff distance and the accurate vehicle speed at the moment of collision are known, assuming that the passenger movement after the collision is linear.

Certain improvements in calculation take into consideration the fact that the traumatizing force (energy) $E_{\text {def }}$ can be calculated if we assume that the pedestrian-car collision is of non-elastic character. From the shock theory inelastic body is known that after the collision both bodies move at equal velocity. Marking this velocity with the value $u$ - is:

$u=\frac{\left(m_{1} v_{1}+m_{2} v_{2}\right)}{\left(m_{1}+m_{2}\right)}$

where:

$m_{1} v_{1}$ - pedestrian momentum;

$m_{2} v_{2}$-car momentum;

The total kinetic energy is:

$E_{\text {def }}=E_{1}^{(1)}+E_{2}^{(1)}-\left(E_{1}^{(2)}+E_{2}^{(2)}\right)$

where:

$E_{1}^{(1)}$ - kinetic energy of pedestrian before impact [Nm]

$E_{2}^{(1)}$ - kinetic energy of car before impact [Nm]

$E_{1}^{(2)}$ ) - kinetic energy of pedestrian after impact [Nm]

$E_{2}^{(2)}$ - kinetic energy of car after impact [Nm]

After some transformations we have:

$E_{\text {def }}=\frac{m_{1} m_{2}}{2\left(m_{1}+m_{2}\right)} \cdot\left(v_{2}-v_{1}\right)^{2}$

Disregard pedestrian movement velocity i.e. $v_{1}=0$

$E_{\text {def }}=\frac{m_{1} m_{2}}{2\left(m_{1}+m_{2}\right)} \cdot v_{2}^{2}$

\subsection{MECHANICAL MODEL OF PEDESTRIAN}

In order to show the possible mechanical impact of the dynamic moment of pedestrian body inertia on the consequences of their movement the pedestrian body model presented in Figure 5 will be assumed. 
In this example the human body is considered to be a homogeneous parallelepiped (stick) of length I and mass $m$. The joint around which the body can rotate is the upper ankle (designated with 0 ) whose rotation axis is perpendicular to the drawing. The body is believed to be at rest before the impact, and the occurring movement is considered flat (in the plane of the image). If due to action of force $F$ the body starts to self-rotate around axis 0 , then the moment around the point equals

$M=F \cdot(a+s)$

It causes acceleration, and in the beginning there is no angular velocity $\omega$. So there is only translation inertia force distributed per body particles, and the resultant of these distributed forces is horizontal force $L$ which acts in the centre of impact (centre of percus sion P) according to the drawing (Figure 5) [3].

The system will be in balance without any horizontal reaction in joint 0 , since the indicated forces act in the same direction, and this is fulfilled if the following condition is met

$a=\frac{i_{a}^{2}}{s}=\frac{J_{s}}{m s}$

where:

a -distance of the percussion centre from the body centre of gravity,

$S$-distance from ankle $\mathrm{O}$ to gravity $\mathrm{S}$.

Let us look now at the model according to the dimensions presented in Figure 5, the order of position sizes of the impact centre.

The moment of inertia of the body with respect to the centre of gravity $S$ is approximately with mass $m=80 \mathrm{~kg}$ and height $I=1.7 \mathrm{~m}$
$J_{S}=\frac{m l^{2}}{12}=19.26\left[\mathrm{kgm}^{2}\right]$

so that the distance of the percussion centre from the body centre of gravity is $a=\frac{19.26}{80 \cdot 0.844}=0.285[\mathrm{~m}]$

i.e. measured from the ground the distance

$k=s+a$

or numerically $k=0.93+0.286=1.216[\mathrm{~m}]$

Based on this simple analysis it is obvious that, if the impact acts at that level of the human body measured from the ground, then only two forces $F$ and $L$ will occur. However, in case the force acts below or above the percussion point positive or negative couple will occur and the body movement will be composed both of translation and rotation.

Consequently, it may be concluded that for studying the throw-off in case of a traffic accident one should take into consideration also the rotation movement as well as the current position of the body at the moment of collision since the dynamic moments of inertia have a significant influence on the body movement.

\section{MOVEMENT OF THE PEDESTRIAN BEFORE AND AFTER COLLISION}

From the very title of the section it is obvious that this manner of the pedestrian movement can be divided into two parts, as follows:

- period before collision, when the pedestrian is standing, walking, running and the similar, and

- period when hit by the vehicle the pedestrian falls on the vehicle or is thrown off and flies through the air falling eventually on the ground and there continues to move or stays motionless [9].

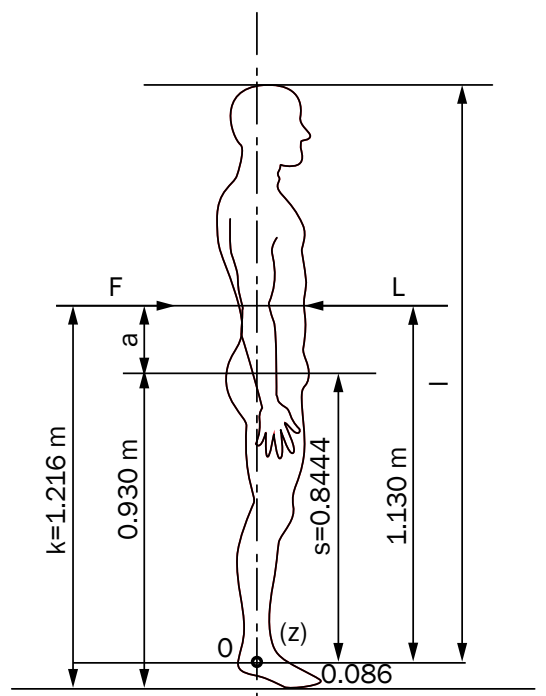

Figure 5 - Simplified human body model to calculate inertia moment and dimensions of average-selected human model (S - gravity, $L$ - horizontal force) 
As it is known, the mathematical formulation of describing the human movement while walking is very complex and has remained still an unsolved problem to the present, at least in the exact meaning of the concept of solution. The reason is a very high number of the degrees of freedom of movement of the human locomotor apparatus, even when neglecting the movement of single body parts.

Human's walk is a very complex mechanical task and the composition of mathematical models for its description has until today remained only on the simplest examples. Apart from the very high number of degrees of freedom of movement (about 250), this is stipulated also by numerous other initial states and knowing of physical properties. This was at the same time the reason why other methods were developed in order to describe the movement: motography, kinetography, etc. which do not contain the parameters for mechanical description of the movement $[2,4]$.

However, for the formation of certain perceptions about the problems that occur in the human walk the elementary ideas will be considered. Figure 6 shows the scheme of the planar form of describing the human walk. This means at the same time that the solution of such a simplified mechanical system requires the knowledge of so many equations in order to be able to define it. It should be added here, for the sake of completeness, that for instance the movement of the arm has been considered as a system with two degrees of freedom of movement, whereas in real conditions it has about 30 degrees of freedom of movement.



Figure 6 - General presentation of the human body with simplified method of load when walking

In our scientific literature Ruszkowski gave a very efficient and comprehensive description of the normal and disturbed walk emphasising especially the biomechanical basis of the analysis of normal walk [6]
However, regardless of the impossibility to solve the problem, there is something from all this that can be used for our needs, which is the possibility of determining the speed of walk in a direction, then knowing the distribution of feet forces on the ground and finally the fact that the function of walking is done in a symmetric and very harmonious movements of all body parts. This means that the human walk by measured speed along a flat surface is a rhythmic movement with a sequence of alternate movements of both legs forward. The mentioned alternate movements by feet are called a step. The exact definition of a step in literature has not been completely uniform yet. By analysing the human walk in the above manner, it is concluded that walk in mechanical sense is a cyclical series of losing and constant regaining of balanced condition of the organism as a mechanical system. In other words, when a human while walking stands on one foot, while the second leg is in the phase of swinging, then it starts to fall to the side where there is no support; however, they are prevented from falling by stepping in the later phases in the walk on the other foot. This method of thinking is emphasised here since in our opinion it is not irrelevant in which period of the step the pedestrian is hit by a car in case of collision.

The pedestrian speeds of movement are naturally dependent also on the age differences and the gender as well as on whether the pedestrian is carrying any load, and whether they are walking alone or next to somebody, etc. (Figure 7) [5]

It is assumed here that prior to human-vehicle collision, the human and the vehicle move in a uniform rectilinear manner as presented in Figure 7 . After the collision the human body is thrown off in a curvilinear manner in the direction of the movement of the vehicle.

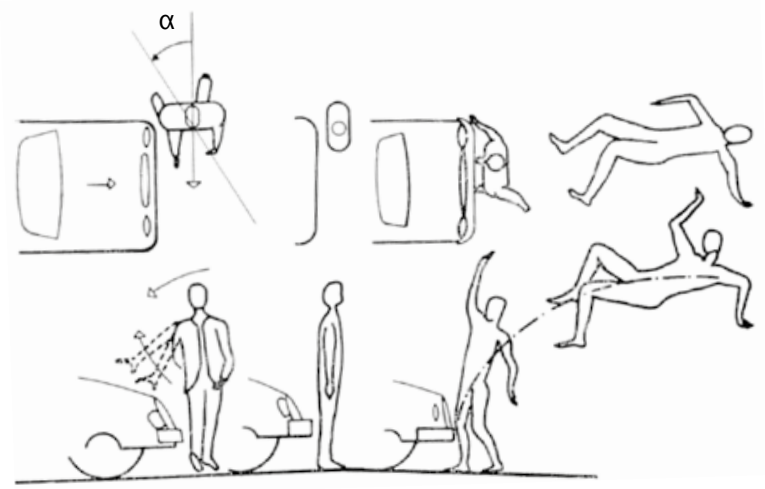

Figure 7 - Examples of initial conditions of the movement of humans and vehicles at the moment of collision

The oncoming vehicle can hit the pedestrian at different heights in relation to the road level which naturally depends on the type and form of the vehicle, and also on the anthropometric characteristics of the 
pedestrian. The position of the resulting impact force $F$ at vehicle impact on the pedestrian depends primarily on the shape of the front part of the vehicle, and then also on the size of the pedestrian body, distribution of its masses including also the position of its centre of masses. There are four different shapes of the front part of the vehicle in use (wedge shape, pontoon shape, semi-case, and case).

Studies $[7,13,14,15,16,17]$ have shown that when secondary impact is considered the wedge and case shape of the vehicle are unfavourable from the aspect of traffic safety (in case of the wedge shape of the vehicle the pedestrian falls from a relatively big height to the base, and considering case shape, the throw-off speed of the pedestrian body that slides along the road is high). Therefore, from the viewpoint of the secondary impact, the pontoon shape of the vehicle with gently curved upper edges and relatively longer front part is the most favourable from the aspect of safety $[10,11]$. It should be mentioned here that the pedestrian experiences the severest injuries during the primary impact. After the thrown off pedestrian body hits the ground; it will continue to slide for some time before stopping. At vehicle collision, the pedestrian body increases its speed to the speed that is almost equal to the speed of the vehicle at the moment of impact, i.e. during the primary impact. The pedestrian body loses this speed during the secondary impact on the base and when sliding along the base. While sliding along the base depending on the type and condition of the surface, as well as the pedestrian clothing, the thrown-off body moves along the surface at an average deceleration of about $6 \mathrm{~m} / \mathrm{s}^{2}$ [18]. During the flight of the thrown-off pedestrian body while it is sliding along the road the pedestrian can hit a barrier or can be run over. Such impact on the pedestrian is usually called tertiary impact. Should this kind of impact occur, then it can change significantly the movement of the thrown-off body.

The spatial movement of humans, after being thrown off by the vehicle, generally consists of the translation movement and of the rotation movement around a number of sequential current rotation axes. If the action of muscles causes secondary rotation movement of one system member, then the remaining part of the organism starts also the secondary rotation in the opposite sense. Here the increments of kinetic moments of both secondary rotating parts are equal in size and opposite per direction, so that the sum of kinetic moments is unchanged. This is of course possible if no external forces change the kinetic moment of force. It should be also emphasised here that all rotation axes of the pedestrian body parts pass through the centre of system masses. These axes are usually called free system axes.
Methods of managing movement about the axis are based on the combination of the movements of single parts of the biomechanical system, and can be divided into simple rotations around one axis and into complex rotations about several axes. Simple rotation represents in itself the stiffening of the body and then its relaxation around the longitudinal axis.

The above-mentioned movements of body elements have their anatomic constraints which can quite naturally affect the total movement of pedestrians in a traffic accident.

In accordance with the law on conservation of kinetic moment one can affect the body rotation speed, which is done by the change of the dynamic inertia moment of the system. It is also possible to reduce the rotation moment by changing the body posture using internal forces.

\section{CONCLUSION}

Based on the presented analysis of the biomechanical behaviour of the pedestrian body in the process of movement in case of traffic accident it is obvious that significant factors for the character of movement are the starting conditions and configuration of pedestrian body at the moment of the deformation period. This way complicates the method of calculating the exact movement description, since one has to take into consideration also the method of distribution of pedestrian body masses during their movement through space, resulting in the need for additional study of dynamic anthropometric values that would serve in calculations in investigating traffic accidents.

By studying the possible application of anthropometric data in the investigation procedure of traffic accidents involving vehicles and pedestrians, it has been determined that in the current literature there are numerous data, which have, however, a clearly expressed static character. Based on the simple examples and analyses on simplified models of human body the quantitative differences between static and dynamic anthropometric values have been presented, thus also determining the significance of applying such unstudied values.

Special significance of dynamic anthropometric variables results from the fact that it is precisely in the collision process that the principles of dynamic analysis should be applied on the movement of the pedestrian.
Dr. Sc. JASNA GOLUBIĆ ${ }^{1}$
E-mail: jgolubic@fpz.hr
Mr. sc. ZORAN VOGRIN ${ }^{1}$
E-mail: zvogrin@fpz.hr
Dr. Sc. EDUARD MISSONI ${ }^{1}$
E-mail: emissoni@fpz.hr
${ }^{1}$ Sveučilište u Zagrebu, Fakultet prometnih znanosti
Vukelićeva 4, 10000 Zagreb, Hrvatska 


\section{DINAMIČKE ANTROPOMETRIJSKE KARAKTERISTIKE PJEŠAKA PRILIKOM SUDARA S VOZILOM}

\section{SAŽETAK}

U radu se daje osvrt na specifičnosti antropomerijskih karakteristika čovjeka - pješaka prilikom prometnih nesreća u kojima sudjeluju pješak i vozilo. Pri tome je posebno uzeta u obzir konfiguracija ljudskog tijela za vrijeme njegovog gibanja, što je pak povezano uz početne uvjete sudara. Poseban dio biomehanike čovjeka odnosi se na njegovo gibanje, gdje specifičan položaj kao mehanička pojava ima hod čovjeka. Na temelju provedene analize vidljiva je potreba za klasifikacijom antropoloških varijabli putem kojih se mogu računati dinamički momenti inercije čovjeka koji hoda, kao i onoga koji odbačen vozilom u prometnoj nesreći, leti proizvodnom krivocrtnom putanjom. Razvitkom ergonomije, a s njom i sve veće primjene antropometrije, napušta se statička antropometrija s obzirom da se čovjeka smatra visoko varijabilnim u njegovim dimenzijama, što je izuzetno bitno za dinamičku analizu položaja čovjekovog tijela u procesu sudara.

\section{KLUČNE RIJEČI}

antropometrijske karakteristike; pješaci; sudar vozila; dinamičke antropometrijske varijable;

\section{REFERENCES}

[1] Donskoj DD, Zaciorskij VM. Biomechanics [in Russian] Moskva: Fizkultura i sport; 1979.

[2] Muftić O. Mechanics of Living Systems [in Croatian]. Tehnička enciklopedija VII. Zagreb: HLZ; 1983.

[3] Muftić O. Biomechanical Approach to Ergonomics of the Sitting Position [in Croatian]. Agrotehničar. 1984;XX(1):16-28.

[4] Muftic O. About the Possibility of Recording Movement in Ergonomics [in Croatian]. Praktikum Biološke antropologije. Ergonomija. 1983;9.

[5] Rotim F, Bukljaš Z. Elements of Biomechanics for Expertise in Traffic Accidents [in Croatian]. Suvremeni promet. 1983;5(4-5):601-624.
[6] Ruszkowski J. Normal and Disturbed Walk of Humans [in Croatian]. Zagreb: Jugoslovenska medicinska naklada; 1981.

[7] Schmid I, Hofman M. Biomechanics of Pre-collision Tasks of Accident Study [in German]. ATZ; July 1984.

[8] Schvechenberg M, Sharma S. D. Pedestrian and Evacuation Dynamics. Berlin: Springer; 2002.

[9] Šimunović Lj, Ćosić M. Non-motorized Traffic [in Croatian]. Zagreb: Faculty of Traffic and Transport Sciences; 2015.

[10] Peng Y, Chen Y, Yang JK, et al. A study of pedestrian and bicyclist exposure to head injury in passenger car collisions based on accident data and simulations. Safety Science. 2012;50:1749-59.

[11] Ulfarsson GF, Mannering FL. Differences in male and female injury severities in support vehicle, minibus, pickup and passenger car accident. Accid Anal Prev. 2004;36(2):135-47.

[12] Untaroiu CD, Crandall JR, Takahashi Y, et al. Analysis of running child pe $\rightarrow$ destrians impacted by a vehicle using rigid-body. Safety Science. 2010;48:259-67.

[13] Rosén E, Sander U. Pedestrian fatality risk as a function of car impact speed. Accid Anal Prev. 2009;41(3): 536-42.

[14] Rosén E, Stigson H, Sander U. Literature review of pedestrian fatality risk as a function of car impact speed. Accid Anal Prev, 2011;43(1):25-33.

[15] Zhao H, Yin ZY, Chen R, et al. Investigation of 184 passenger car-pedestrian accidents. International of Crashworthiness. 2010;15(3):313-20.

[16] Roudsari BS, Mock CN, Kaufman R. An evaluation of association between vehicle type and the source and severity of pedestrian injury. Traffic Injury Prevent, 2005;6(2):185-92.

[17] Han Y, Yang JK, Nishinoto K, et al. Finite element analysis of kinematic behaviour and injuries to pedestrians in vehicle collisions. International of Crashworthiness, 2012;17(2):141-52.

[18] Karger B, Teige K, Bühren W, DuChesne A. Relationship between impact velocity and injuries in fatal pedestrian-car collisions. Int J Legal Med. 2000;113(2):84-88. 